\title{
En busca de la fuente embólica: endocarditis marántica
}

lone Villar García*

José Eduardo Ramírez Batista**

Alejandro Gutiérrez Fernández**

Federico Castillo Álvarez ${ }^{* * *}$

Pedro María Azcárate Agüero**

* Servicio de Urgencias. Hospital San Pedro. Logroño (La Rioja). España

** Departamento de Cardiología. Hospital San Pedro. Logroño (La Rioja). España

*** Departamento de Neurología. Hospital San Pedro. Logroño (La Rioja). España

Recibido: 05/03/2020

Aceptado: 09/10/2020

En línea: 31/12/2020

Citar como: Villar García I, Ramírez Batista JE, Gutiérrez Fernández A, Castillo Álvarez F, Azcárate Agüero PM. En busca de la fuente embólica: endocarditis marántica. Rev Ecocar Pract (RETIC). 2020 (Dic); 3 (3): 13-15. doi: 10.37615/retic.v3n3a7.

Cite this as: Villar García I, Ramírez Batista JE, Gutiérrez Fernández A, Castillo Álvarez F, Azcárate Agüero PM. The search of the embolic source: marantic endocarditis. Rev Ecocar Pract (RETIC). 2020 (Dic); 3 (3): 13-15. doi: 10.37615/retic.v3n3a7.

\section{Palabras clave \\ $\triangleright$ Endocartitis marántica \\ $\triangleright$ Endocarditis trombótica no bacteriana \\ $\triangleright$ Embolia sistémica}

\section{RESUMEN}

Presentamos el caso de una paciente de 58 años de edad con ictus isquémicos en múltiples territorios que finalmente fue diagnosticada de endocarditis marántica en el contexto del estado protrombótico causado por un carcinoma de endometrio. El diagnóstico de la endocarditis marántica es un gran reto para el clínico debido a que se trata de una enfermedad que suele tener síntomas tardíos y agresivos. La demostración de vegetaciones en el ecocardiograma en ausencia de infección sistémica en pacientes de alto riesgo es la base para el diagnóstico. Es una enfermedad que tiene mal pronóstico a corto plazo, por lo que es crucial tener un alto índice de sospecha clínica.

ABSTRACT
We present the case of a 58-year-old patient with ischemic stroke in multiple territories who was finally diagnosed
with marantic endocarditis in the context of the prothrombotic state caused by an endometrial carcinoma. The
diagnosis of marantic endocarditis is challenging for the clinician because it is a disease that usually has late and
aggressive symptoms. The finding of vegetations on the echocardiogram in the absence of systemic infection in
high-risk patients is the basis for the diagnosis. It is a disease that has a poor prognosis in the short term, so it is
crucial to have a high index of clinical suspicion.

\section{Presentación del caso}

Paciente de 58 años sin antecedentes previos de interés. Ingresó en Neurología para estudio por parestesias en ambas manos con alteración en la motricidad fina de 6 meses de evolución, asociado a desorientación y pérdida de peso.

En la exploración física destacaban desorientación y bradipsiquia. Tras una tomografía computarizada (TC) craneal urgente sin hallazgos patológicos, se realizó una resonancia magnética $(R M)$ cerebral que objetivaba múltiples infartos agudos/subagudos en ambos hemisferios cerebrales y en cerebelo sugestivos de origen embólico. El electrocardiograma (ECG), la angio-TC de troncos supraaórticos, la eco Doppler transcraneal, el electroencefalograma y el ecocardiograma basal no mostraron alteraciones patológicas (Vídeo 1). Se solicitó también una analítica completa en la que destacó elevación de marcadores tumorales CA-15.3, CA-125 y CEA, por lo que se hizo un despistaje de una neoplasia oculta con TC toraco-abdomino-pélvica donde llamaban la atención múltiples zonas hipodensas e hipocaptantes a nivel renal y en bazo sugestivas de defectos de perfusión isquémicos, y un útero de aspecto miomatoso. Fue valorada por Ginecología, que solicitó una RM pélvica en la que se apreciaba una imagen sospechosa de neoformación endometrial. La biopsia obtuvo material compatible con carcinoma seroso y se demostró diseminación ganglionar pélvica por medio de PET oncológico. Tras los resultados, se realizó una histerectomía radical con linfadenectomía pélvica, paraaórtica y omentectomía. Con el diagnóstico anatomopatológico de carcinoma seroso de endometrio de alto grado e ictus isquémicos multiterritoriales secundarios a estado protrombótico, fue dada de alta con tratamiento antiagregante pendiente de iniciar tratamiento quimioterápico.

Al mes del alta, acudió de nuevo a Urgencias por incapacidad para la lectura y la escritura, junto con deterioro de su capacidad funcional. En la RM, se diagnosticó un accidente cerebrovascular (ACV) isquémico hemisférico izquierdo (Figura 1), por lo que se inició tratamiento anticoagulante con heparina de bajo peso molecular (HBPM) y se solicitó un ecocardiograma transesofágico (ETE) 
para descartar una fuente embólica. Antes de poder realizar el estudio, presentó un nuevo ictus con afasia completa y hemiplejia derecha con hipodensidad en corteza insular y opérculo frontal izquierdos compatibles con lesión isquémica aguda-subaguda en TC. Finalmente, se realizó ETE, donde se apreciaron imágenes compatibles con endocarditis marántica sobre válvula mitral nativa con insuficiencia mitral ligera (Vídeos 2 a 6). La paciente fue trasladada a un centro de convalecencia, donde, tras una evolución tórpida, finalmente falleció.

\section{Estudio por imagen}

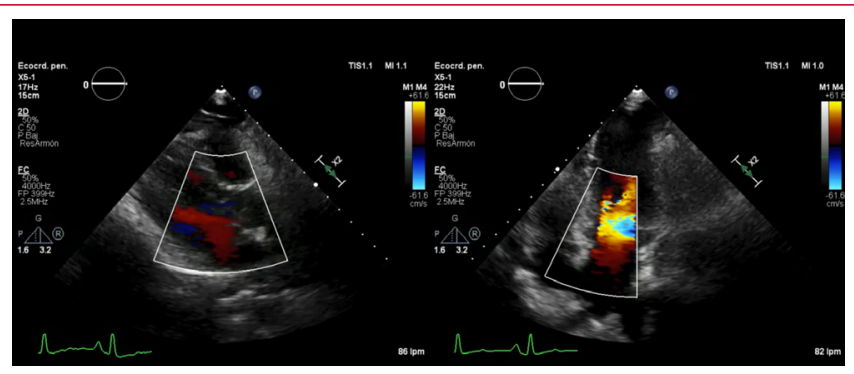

Vídeo 1. Ecocardiograma transtorácico, eje largo color y 4 cámaras color. No se observan regurgitaciones valvulares. Las válvulas mitral y aórticas no mostraban lesiones. Se administró también suero salino agitado por vena antecubital izquierda y no se observó paso de agregados de microburbujas a cavidades izquierdas (septo interauricular íntegro)



Figura 1. RM cerebral. La flecha señala lesión isquémica perisilviana izquierda de evolución aguda-subaguda; las puntas de flecha, lesiones isquémicas perisilvianas derecha y frontal derecha de evolución crónica

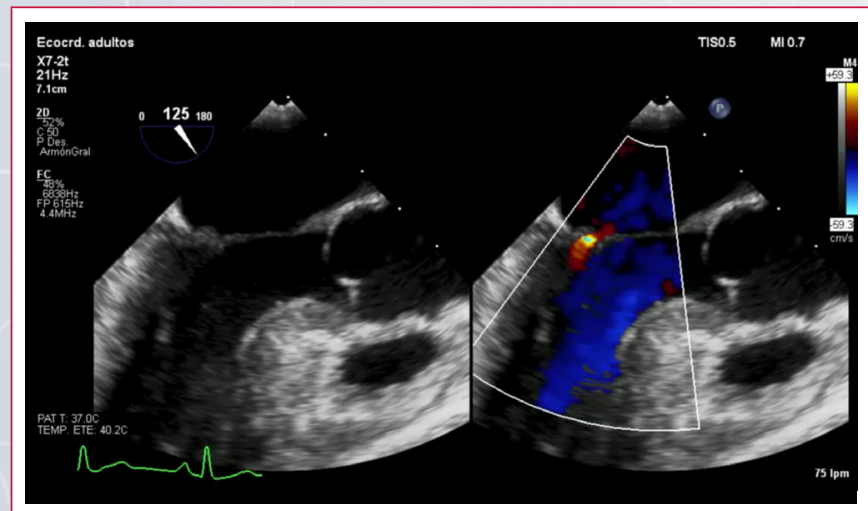

Vídeo 2. ETE, eje largo. Imágenes compatibles con endocarditis marántica (trombótica no bacteriana) sobre válvula mitral nativa. Se observan varias estructuras móviles y sésiles sobre los segmentos A2 y P2 (líneas amarillas). Estas estructuras miden $6 \mathrm{~mm}$ en el segmento $A 2$ y $5 \mathrm{~mm}$ en el segmento $\mathrm{P} 2$. Se observa una insuficiencia mitral ligera

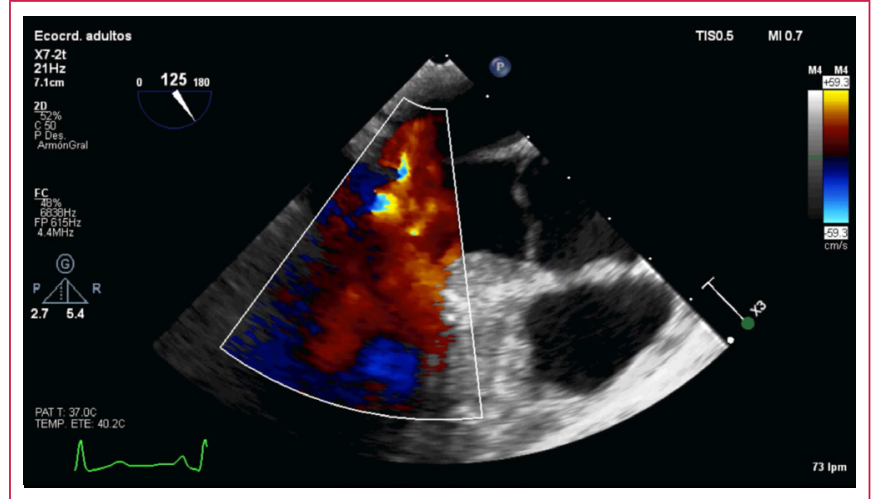

Vídeo 3. ETE, eje largo primero sin color y luego con color. Mismos hallazgos que en el Vídeo 2

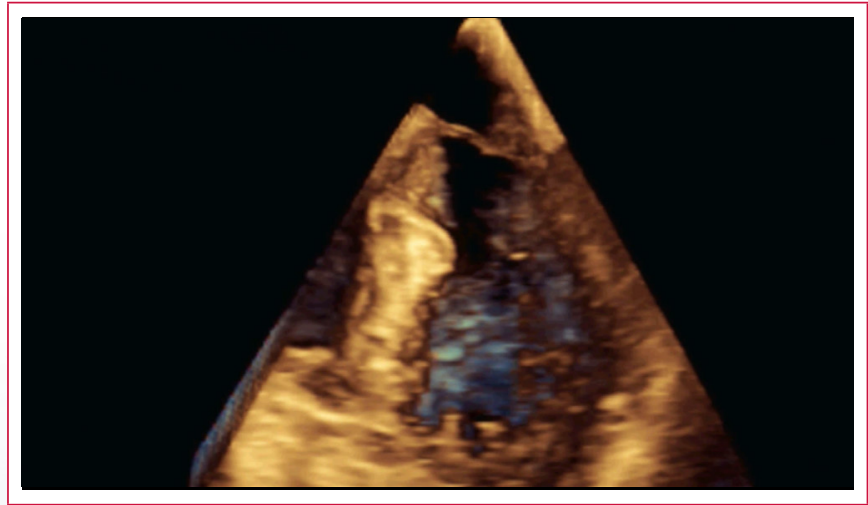

Vídeo 4. ETE 3D 4 cámaras, detalle de los velos mitrales. Endocarditis marántica con afectación de los velos anterior y posterior mitral

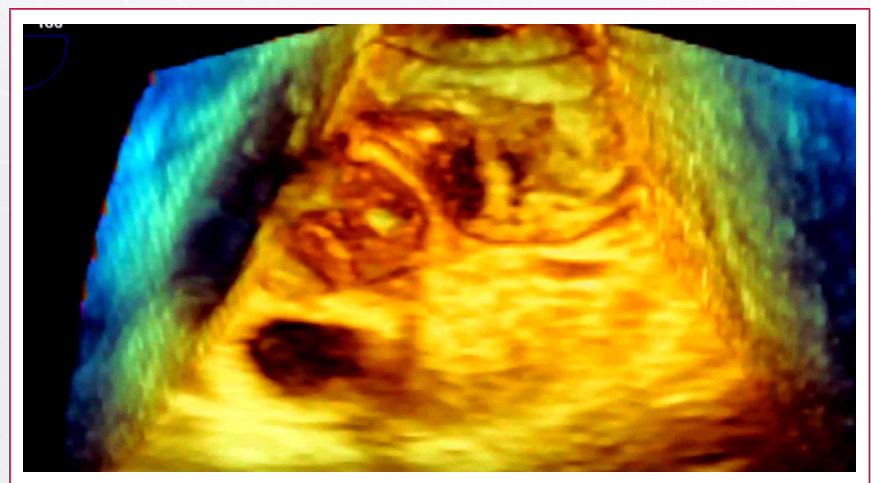

Vídeo 5. ETE 3D, vista de la válvula mitral desde la aurícula izquierda

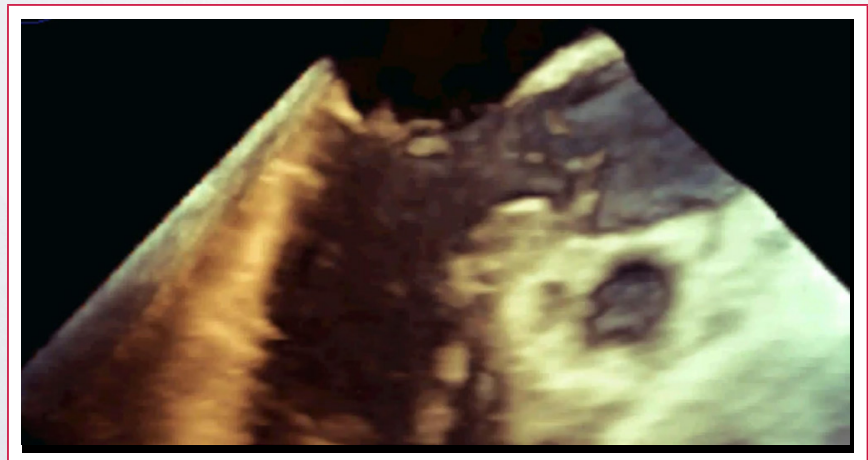

Vídeo 6. ETE 3D, eje largo. Se observan varias estructuras sésiles y móviles sobre los velos mitrales anterior y posterior. Se destacan dos mediante círculos amarillos en el vídeo 


\section{Discusión}

La endocarditis trombótica no bacteriana (ETNB), también conocida como endocarditis marántica o de Libman Sacks, es una entidad poco frecuente que produce lesiones no infecciosas de las válvulas cardiacas ${ }^{(1)}$. Es una enfermedad que se asocia habitualmente a neoplasias en estadio avanzado, sobre todo a adenocarcinomas ( $y$, dentro de ellos, al mucinoso y pancreático) o a enfermedades inflamatorias, principalmente el lupus eritematoso sistémico (LES) y, menos frecuentemente, el síndrome antifosfolípido (SAF) y la artritis reumatoide (AR). Predomina entre la cuarta y octava década, sin diferencias en cuanto al sexo.

El factor que inicia su patogénesis es desconocido, pero se cree que en su desarrollo es crítica la aparición de daño endotelial causado por citocinas inflamatorias circulantes y la presencia de un estado de hipercoagulabilidad, lo que contribuye al depósito de trombos estériles compuestos por plaquetas y fibrina sobre válvulas cardíacas que previamente pueden estar sanas o enfermas. Habitualmente, afecta a las válvulas del lado del corazón (aórtica 66\% o mitral $25 \%$, menos frecuente ambas). Estas lesiones, a diferencia de las causadas por la endocarditis bacteriana, tienen tendencia a disgregarse fácilmente, por lo que tienen mayor tendencia a la embolización.

Muchas veces, el diagnóstico se realiza como un hallazgo del estudio histopatológico post mortem. Sin embargo, en muchos pacientes (hasta el 50\% de los casos), se manifiestan clínicamente en forma de embolias. La enfermedad produce con mayor frecuencia embolismos de localización periférica (bazo, riñón, piel o extremidades), que pueden presentarse, respectivamente, como dolor en flanco, hematuria, erupción cutánea o isquemia digital), aunque la sospecha diagnóstica es mayor cuando producen embolismos del sistema nervioso central o coronario debido a la gravedad de los síntomas. Es mucho menos frecuente encontrar casos con disfunción valvular por insuficiencia aórtica o tricuspídea. Se debe descartar endocarditis infecciosa, por lo que se ha de realizar una analítica completa, al menos tres sets de hemocultivos, determinación de PCR y serologías de endocarditis con resultados negativos. También se tiene que hacer estudio de hipercoagulabilidad completo y cribado de neoplasia oculta.

En los pacientes con clínica neurológica, clínica neurológica, la TC o la RMN cererbral muestran frecuentemente ACV isquémicos múltiples, que son recurrentes en un $50 \%$ de los casos. Si la sospecha clínica es alta, debe realizarse ecocardiograma transtorácico (ETT) para descartar la presencia de vegetaciones y, si éste no es diagnóstico, debe ampliarse el estudio, como en nuestro caso, con un estudio transesofágico, que tiene mayor sensibilidad para detectar vegetaciones de menor tamaño, aunque no diferencia su composición histológica. El diagnóstico definitivo lo establece la anatomía patológica de muestras quirúrgicas o de autopsia, pero este procedimiento no se realiza de rutina.

Por tanto, ante la escasez de síntomas y la presentación tardía, el diagnóstico de ETNB supone todo un reto para el clínico. Se debe sospechar su presencia en pacientes con ictus isquémicos o episodios de isquemia coronaria en pacientes con neoplasia, LES o SAF, en pacientes con ictus isquémicos embólicos multiterritoriales de etiología indeterminada (como en nuestro caso); o en pacientes con posible endocarditis infecciosa con mala respuesta al tratamiento antibiótico.

El tratamiento de la ETNB consiste, fundamentalmente, en la anticoagulación sistémica y la terapia de la enfermedad de base, reservándose la cirugía para casos concretos ${ }^{(2)}$. La anticoagulación está indicada en todos los pacientes, independientemente de la presencia de sintomatología neurológica, debido al alto riesgo embolígeno por mayor fragilidad de las vegetaciones (previa realización de una prueba de imagen que descarte hemorragia intracraneal), y debe continuarse de manera indefinida. El tratamiento quirúrgico (escisión de la vegetación o reemplazo valvular) tiene unas indicaciones similares a las de la endocarditis infecciosa, además de la prevención de la embolia recurrente. Debe valorarse el beneficio/riesgo individual, y es importante la preservación del tejido valvular ya que no existe una infección activa ${ }^{(3)}$.

Sin embargo, el pronóstico de esta patología, a pesar del tratamiento, es sombrío, debido tanto a la morbilidad por disfunción neurocognitiva como a la muerte por embolia recurrente extensa o neoplasia subyacente avanzada.

En nuestro caso, la paciente debutó con clínica neurológica en ausencia de un diagnóstico previo de enfermedad tumoral, lo que enlenteció el proceso diagnóstico. La ausencia de fiebre o soplos cardíacos hizo que no se sospechara una posible lesión valvular. Además, el diagnóstico de neoplasia endometrial, que precisaba tratamiento quirúrgico, retrasó el inicio de la anticoagulación terapéutica. La paciente presentó fenómenos embólicos cerebrales extensos de repetición y, a pesar del tratamiento de la enfermedad de base y del tratamiento anticoagulante, presentó una evolución tórpida con desenlace fatal. El caso es un buen ejemplo de las muchas dificultades que la enfermedad presenta, tanto en el diagnóstico como en el tratamiento.

\section{Conclusión}

El diagnóstico de la endocarditis marántica supone un gran reto para el clínico, debido a que suele producir síntomas de aparición tardía y muy agresivos, lo que hace que sea una enfermedad de mal pronóstico a corto plazo.

La demostración de vegetaciones en el ecocardiograma, en ausencia de infección sistémica en pacientes de alto riesgo, es la principal pista que lleva al diagnóstico.

\section{Ideas para recordar}

- La endocarditis marántica es una entidad rara, de difícil diagnóstico y con pronóstico sombrío.

- Debemos tenerla en cuenta dentro del diagnóstico diferencial del ictus cardioembólico o la embolia coronaria, especialmente en pacientes con enfermedades sistémicas proinflamatorias, principalmente neoplasias sólidas y LES.

\section{Bibliografía}

1. Liu J, Frishman WH. Nonbacterial thrombotic endocarditis: pathogenesis, diagnosis, and management. Cardiol Rev 2016; 24 (5): 244-247.

2. Mazokopakis EE, Syros PK, Starakis IK. Nonbacterial thrombotic endocarditis (marantic endocarditis) in cancer patients. Cardiovasc Hematol Disord Drug Targets 2010; 10 (2): 84-86.

3. Parker N, Atallah R, Ojile N, et al. Nonbacterial thrombotic endocarditis. Kans J Med 2020; 13: 61-62. 